\title{
Novel clinical applications of state-of-the-art multi-slice computed tomography
}

\author{
J. D. Schuijf · V. Delgado · J. M. van Werkhoven · F. R. de Graaf • \\ J. E. van Velzen · M. M. Boogers · L. J. Kroft · A. de Roos · J. W. Jukema · \\ J. H. C. Reiber · E. E. van der Wall · J. J. Bax
}

Received: 8 October 2008/ Accepted: 5 January 2009/Published online: 21 January 2009

(C) The Author(s) 2009. This article is published with open access at Springerlink.com

\begin{abstract}
Recent years have witnessed a rapid development of multi-slice computed tomography (MSCT) technology. The number of detector rows has increased from 4-slices to the current availability of 64-slice and even 320-slice systems. In addition, images are acquired with thinner slices and faster
\end{abstract}

V. Delgado is financially supported by the Research Fellowship of the European Society of Cardiology. J. M. van Werkhoven is financially supported by a research grant from the Netherlands Society of Cardiology (Utrecht, The Netherlands). F. R. de Graaf is co-supported by the Dutch Technology Foundation STW (Utrecht, The Netherlands), applied science division of NWO and the Technology Program of the Ministry of Economic Affairs, grant number 10084. J. E. van Velzen is supported by the Netherlands Heart Foundation (The Hague, The Netherlands), grant number 2007B223. Mark M. Boogers is supported by the Dutch Heart Foundation (The Hague, The Netherlands), grant number 2008R004. Jeroen J. Bax has research grants from Medtronic (Tolochenaz, Switzerland), Boston Scientific (Maastricht, The Netherlands), BMS medical imaging (N. Billerica, MA, USA), St. Jude Medical (Veenendaal, The Netherlands), Biotronik (Berlin, Germany), GE Healthcare (St. Giles, United Kingdom), and Edwards Lifesciences (Saint-Prex, Switzerland).

J. D. Schuijf · V. Delgado - J. M. van Werkhoven ·

F. R. de Graaf · J. E. van Velzen · M. M. Boogers ·

J. W. Jukema · E. E. van der Wall · J. J. Bax ( $\square)$

Department of Cardiology, Leiden University Medical

Center, Albinusdreef 2, P.O. Box 9600, 2300 RC Leiden,

The Netherlands

e-mail: j.j.bax@lumc.nl

J. D. Schuijf

e-mail: J.D.Schuijf@lumc.nl rotation times resulting in substantially improved image quality and diagnostic accuracy. Simultaneously, effective dose reduction acquisition techniques have been developed allowing considerable reduction of the radiation dose. Conceivably, these advancements may allow further expansion of the use of MSCT beyond the visual assessment of the presence or absence of significant coronary artery disease. Indeed, a particular advantage of the technique is that in addition to evaluation of the coronary arteries it also allows assessment of cardiac structures and function. The purpose of the current review is to discuss several novel applications of cardiac MSCT, including stenosis quantification, atherosclerotic plaque imaging and prognostification as well as imaging of left ventricular function, aortic and mitral valve anatomy using state-of-the-art technology.

Keywords Imaging · Computed tomography

\author{
L. J. Kroft · A. de Roos · J. H. C. Reiber \\ Department of Radiology, Leiden University Medical \\ Center, Albinusdreef 2, P.O. Box 9600, 2300 RC Leiden, \\ The Netherlands \\ J. M. van Werkhoven · J. E. van Velzen . \\ M. M. Boogers · J. W. Jukema - E. E. van der Wall \\ Interuniversity Cardiology Institute of the Netherlands, \\ Utrecht, The Netherlands
}




\section{Introduction}

Recent years have witnessed a rapid development of multi-slice computed tomography (MSCT) technology. The number of detector rows has increased from 4-slices to the current availability of 64-slice and even 320-slice systems. In addition, images are acquired with thinner slices and faster rotation times resulting in substantially improved image quality and diagnostic accuracy. Simultaneously, effective dose reduction acquisition techniques have been developed allowing considerable reduction of the radiation dose. Conceivably, these advancements may allow further expansion of the use of MSCT beyond the visual assessment of the presence or absence of significant coronary artery disease (CAD). Indeed, a particular advantage of the technique is that in addition to evaluation of the coronary arteries it also allows assessment of cardiac structures and function. The purpose of the current review is to discuss several novel applications of cardiac MSCT, including stenosis quantification, atherosclerotic plaque imaging and prognostification as well as imaging of left ventricular (LV) function, aortic and mitral valve anatomy using state-of-the-art technology.

\section{Developments in imaging of the coronary arteries}

\section{Quantification of the degree of stenosis on MSCT}

High diagnostic accuracies to detect significant coronary artery stenoses have been reported for MSCT as compared to invasive coronary angiography [1]. Of note, these data are based on visual assessment of the degree of stenosis using in general a cut-off of $50 \%$ luminal narrowing or more. In contrast, no validated quantitative approach is currently available which is considered to be a major limitation of the technique. Indeed, the opportunity to obtain a more precise measure of the degree of stenosis, similar to quantitative coronary angiography (QCA), would be highly beneficial in terms of diagnostic accuracy, reproducibility and subsequent therapeutic management decisions. However, the limited temporal and spatial resolution of MSCT as compared to invasive coronary angiography may pose substantial difficulties. Not surprisingly, previous attempts to quantify stenosis of coronary arteries have been disappointing [2, 3]. Leber and colleagues recently evaluated the diagnostic accuracy of stenosis quantification in 59 patients who were underwent both 64-MSCT and invasive coronary angiography [2]. In 55 patients, all coronary artery segments (825 segments, based on a 15 segment model) could be visualized and subsequently quantified on MSCT. Overall, only a moderate correlation $(n=825$, $r=0.54) \quad$ was observed for diameter stenosis between measurements on MSCT and QCA. In particular, poor diagnostic accuracy of MSCT was observed for distal segments as compared to proximal and mid segments of the coronary arteries. With regard to plaque type, a tendency to overestimate the degree of stenosis in the presence of calcium has been identified. Finally, reproducibility appears to be limited as well [2-4].

To some extent, better correlations may be expected by comparing MSCT to true tomographic atherosclerosis imaging techniques, such as intravascular ultrasound (IVUS). Also, the development of more automated algorithms with less manual interference may substantially improve accuracy and reduce interobserver variability [5, 6]. An example of analysis with automated quantification software developed at our own center is provided in Fig. 1.

Recently, Bruining and coworkers reported their observations using automated coronary plaque measurements on MSCT angiography in comparison to IVUS in 48 patients [5]. Interestingly, the authors demonstrated that automated lumen detection on MSCT angiographic examinations was superior to manual assessment of vessel contours with good reproducibility. Nevertheless, automated quantification of MSCT systematically underestimated coronary plaque, in line with previous investigations. Accordingly, although the potential of automated quantification of stenosis is evident, further developments remain needed before these algorithms can be used in daily clinical practice. In addition, one needs to realize that although assessment of significant stenosis as compared to invasive coronary angiography may improve by the availability of quantitative algorithms, prediction of ischemia will remain limited. Indeed, several studies comparing MSCT coronary angiography with functional testing revealed a large discrepancy between techniques [7, 8]. In line with previous comparisons with invasive coronary angiography, many significant 
Fig. 1 Example of automated quantification of the degree of stenosis using dedicated software (QAngio ${ }^{\circledR}$ CT, Medis, Leiden, the Netherlands). Initially, segment definition is performed using proximal and distal markers as illustrated in a. Automated contour detection is performed in longitudinal (b) and transversal (c) views as previously described [6]. Finally, as shown in d, quantification of stenosis is based on differences between the reference line (red line) and contour diameter (yellow line), similar to traditional QCA
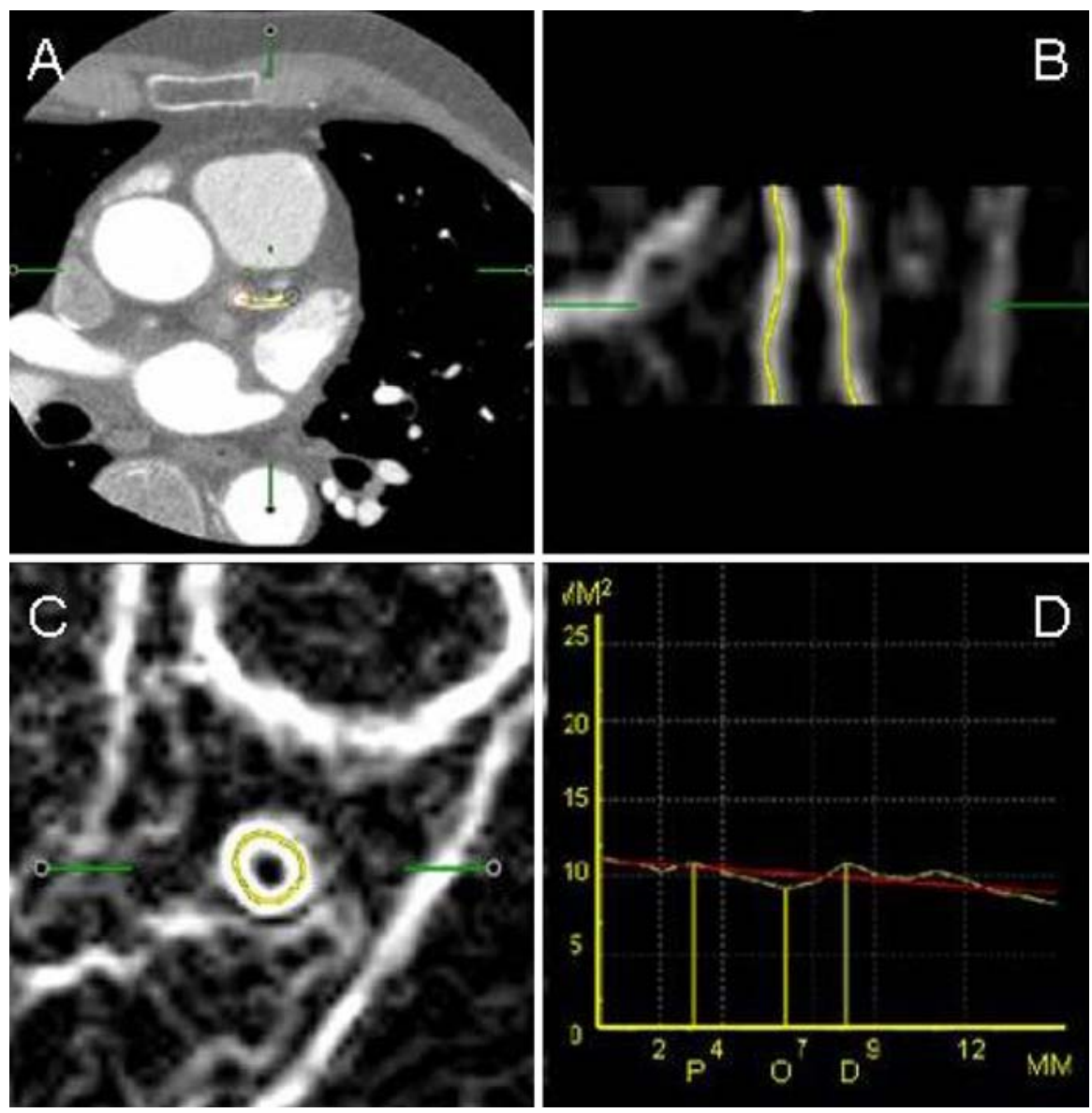

stenoses on MSCT did not result in ischemia on functional testing. Moreover, Meijboom et al. recently demonstrated that even quantitative assessment resulted in poor correlation with intracoronary fractional flow reserve, confirming that anatomical assessment cannot predict the hemodynamic significance of a coronary stenosis [9]. Accordingly, further evaluation with functional testing remains essential for angiographically intermediate lesions prior to referral for invasive coronary angiography and revascularization.

\section{Plaque imaging with MSCT}

An emerging feature of MSCT that receives increasing interest is its capability to non-invasively visualize atherosclerosis, as illustrated in Fig. 2. Despite the development of dedicated risk assessment tools, a large number of patients without any prior symptoms experience acute myocardial infarction or even sudden death [10]. These unexpected adverse cardiac events emphasize the significance of detection of underlying coronary atherosclerosis. Moreover, it appears that not only plaque severity in terms of percentage stenosis but also plaque composition is an important determinant of acute coronary events. Plaques with a large necrotic core and thin fibrous cap (identified by histology) appear to be more vulnerable to rupture and can be a substrate for atherothrombotic events [11]. Until recently, evaluation of potentially vulnerable lesions was only possible by using invasive modalities such as IVUS, elastography and optical coherence tomography. However, recent studies have demonstrated the potential of MSCT to evaluate differences in atherosclerotic plaque burden and composition noninvasively [12-14]. Indeed, an important advantage of the technique, as compared to invasive coronary angiography, is that it visualizes not only luminal narrowing but also atherosclerotic plaque content. Consequently, extensive effort is currently undertaken to determine in more detail what observed differences in plaque morphology on MSCT represent. 
Fig. 2 Evaluation of atherosclerotic plaque with MSCT. a A curved multiplanar reconstruction of the right coronary artery (RCA), obtained by 320slice MSCT without evidence of atherosclerosis. In contrast, the curved multiplanar reconstruction (320-slice MSCT) of the RCA in $\mathbf{b}$ shows the presence of diffuse atherosclerosis (arrows). Note that both non-calcified and calcified tissue can be identified
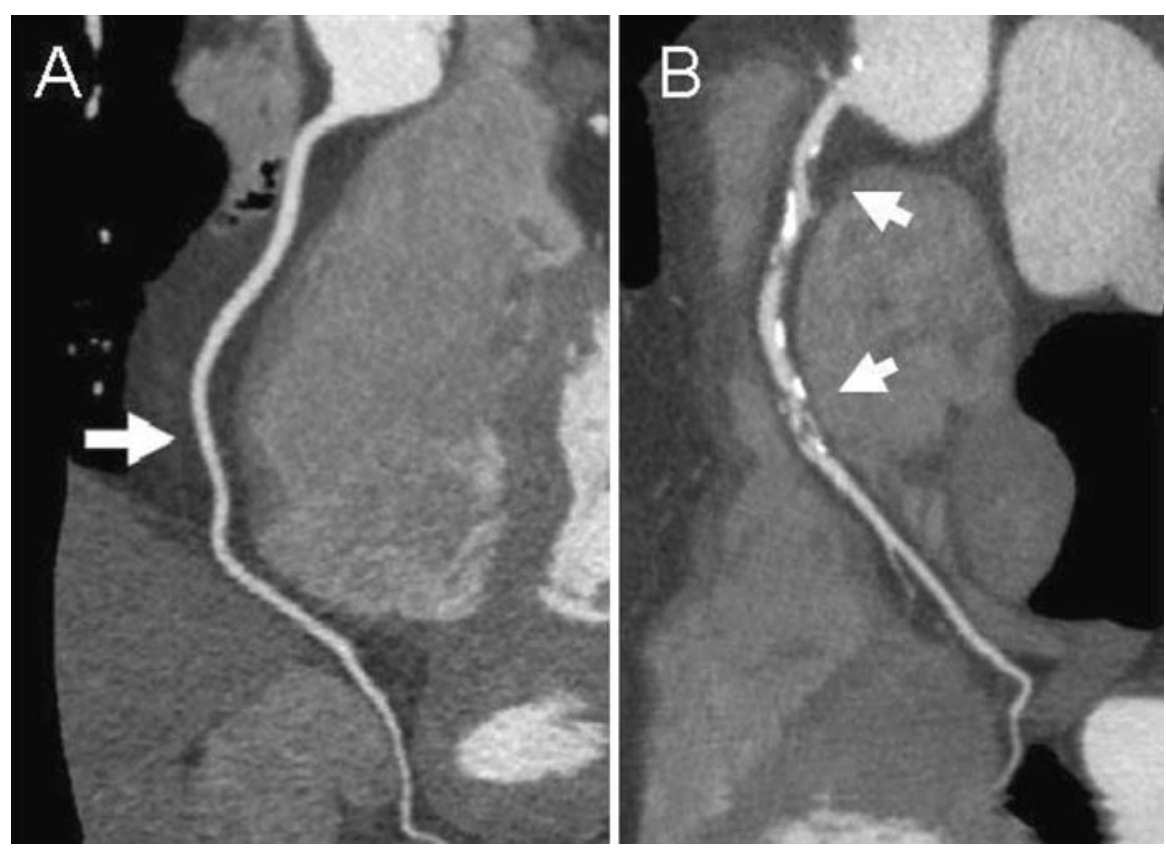

Briefly, three different plaques types can be distinguished by MSCT; non-calcified plaque, mixed plaque and calcified plaque. Calcified lesions appear as bright white dense structures, mixed plaques consist of non-calcified and calcified elements within the same plaque and non-calcified plaques have lower density compared with the contrast-enhanced vessel lumen but without any visible calcification. Comparisons with IVUS have shown that using differences in attenuation values MSCT may indeed reliably differentiate plaque configurations [14]. In a recent study, mean MSCT density of calcified plaque was $516 \pm 198$ Hounsfield Units (HU), while the mean density measured within non-calcified plaques and mixed plaques was $11 \pm 12$ and $78 \pm 21 \mathrm{HU}$, respectively [15]. Further differentiation of noncalcified plaque however may be difficult. Pohle and colleagues demonstrated significant differences between "lipid rich" (mean density of $58 \pm 43 \mathrm{HU}$ ) and "fibrous" plaque (mean of $121 \pm 34 \mathrm{HU}$ ), although the overlap of attenuation values between individual lesions was substantial [16]. Additionally, external factors such as the amount of contrast, body mass index and cardiac output also highly influence attenuation values. As a result, detailed characterization of non-calcified plaque as stable or vulnerable is currently not feasible based on MSCT density measurements alone. Pundziute and colleagues recently compared plaque composition to virtual histology IVUS (VH IVUS) and reported a good correlation between plaque characteristics on MSCT and relative plaque component on VH IVUS [17]. Nevertheless, still small percentages of calcium were observed in lesions deemed to be non-calcified on MSCT. Conversely, in plaques appearing as completely calcified, fibrotic or fibro-fatty tissue is frequently identified on VH IVUS as well. Possibly, initial differentiation into calcified or non-calcified may therefore be more reliable. Based on their appearance, lesions containing calcium may then be further differentiated into large calcification or spotty calcifications, as recently suggested [18]. Interestingly, features of thin capped fibroatheroma (suggesting vulnerability) were most frequently observed in lesions classified as mixed on MSCT. Additionally, Lin and colleagues investigated the relationship of anatomical MSCT variables including plaque composition and extent with functional ischemia on SPECT [19]. The authors observed that mixed plaques were an independent predictor of severely abnormal SPECT studies. These observations suggest that the observation of multiple mixed plaques may possibly confer a higher risk of adverse cardiac events. Moreover, also in retrospective studies comparing plaque morphology on MSCT between patients presenting with acute coronary syndromes 
and stable $\mathrm{CAD}$, relative more non-calcified and mixed plaques have been identified in the former patients [20-23]. However, no robust prospective data are currently available to support this thesis.

At present, it is important to realize that the inferior resolution of MSCT as compared to invasive plaque imaging techniques remains an important limitation. Nevertheless, novel approaches are currently under investigation including dual-energy source MSCT and dedicated contrast agents for improvement in plaque characterization [24, 25]. In addition, sophisticated algorithms to accurately determine plaque volume are under development. Potentially, these algorithms in combination with assessment of plaque component may allow MSCT to play a role in the monitoring of the efficacy of anti-atherosclerotic interventions [26, 27]. Accordingly, although plaque imaging with MSCT represents an intriguing aspect of the technique, available data are scarce and limited to small singlecenter studies. Prospective trials are highly needed to determine whether detailed evaluation of atherosclerosis by MSCT may indeed provide clinically relevant information.

\section{Evaluation of prognosis with MSCT}

Since non-invasive coronary angiography with MSCT is a relatively new technique, only limited data are available concerning its potential prognostic value. In contrast, evaluation of the presence and extent of atherosclerosis by means of coronary calcium scoring (CS) has been possible for a longer period and a considerable amount of evidence is currently available with this technique [28]. In a large study by Shaw et al. CS was obtained in 10,377 asymptomatic individuals who were subsequently followed for a median of 5 years [29]. The authors demonstrated that CS was able to predict all-cause mortality, independent of baseline cardiac risk factors. Recently, the 2007 ACCF/AHA expert consensus document on CS has been published in which a systematic review of the available literature ( $n=27,622$ patients) was performed [28]. Based on these data, the presence of any coronary artery calcium was shown to confer a fourfold increased risk of cardiac death or myocardial infarction $(P<0.0001)$ as compared to the absence of coronary artery calcifications [28]. In contrast, an event rate as low as $0.4 \%$ was observed in patients without any coronary artery calcium. Similar observations were recently reported in a large registry of patients ( $n=25,253$ patients), confirming that an increase in the extent of coronary artery calcium corresponds with an elevated risk for all-cause mortality [30]. Accordingly, knowledge of CS may refine traditional risk stratification and thus guide therapeutic decisions by shifting patients to either a higher or lower risk category. As a consequence, particularly patients deemed at intermediate risk based on traditional risk assessment may benefit from this technique.

Preliminary investigations using MSCT coronary angiography have suggested that this technique may also provide prognostic information [31, 32]. Pundziute et al. assessed the prognostic value of 16- or 64-slice MSCT in a cohort of 100 patients with known or suspected CAD [31]. During a follow-up period of 1 year MSCT was shown to predict the occurrence of events independent of baseline risk factors. In a larger study by Min et al., 1,127 patients undergoing 16-slice MSCT were evaluated during a follow-up period of 2 years [32]. As illustrated in Fig. 3, event rates for all-cause mortality ranged between $0.3 \%$ for patients with none or mild atherosclerosis (stenosis <50\%) on MSCT to $15 \%$ in patients with mild to moderate left main disease.

Several studies have addressed the incremental prognostic value of anatomic imaging when used in addition to myocardial perfusion imaging (MPI). In the studies by Ramakrishna et al. and Anand et al., respectively 835 and 510 patients were enrolled who underwent both CS and MPI [33, 34]. The combination of these techniques resulted in a synergistic prediction of cardiovascular events. Rozanski and colleagues assessed the combined use of CS and MPI in a large cohort of 1,153 asymptomatic patients [35]. Interestingly, in patients with normal myocardial perfusion on MPI $(n=1,089)$, the observation of a high CS was not associated with an increased risk for cardiac death and myocardial infarction during a mean follow-up of $32 \pm 16$ months. In contrast, Schenker et al. recently observed in symptomatic patients that the risk of allcause mortality and myocardial infarction increased with increasing CS, both in patients with normal and in patients with abnormal perfusion on MPI [36]. Similarly, van Werkhoven et al. recently demonstrated that the information on plaque burden and composition obtained by MSCT coronary angiography had incremental prognostic value over MPI [37]. Accordingly, 
Fig. 3 Prognostic value of MSCT. Cumulative survival curves in relation to the extent of atherosclerosis plaque (as assessed based on the Duke Prognostic Coronary Artery Disease Index). Reprinted with permission from reference [32]

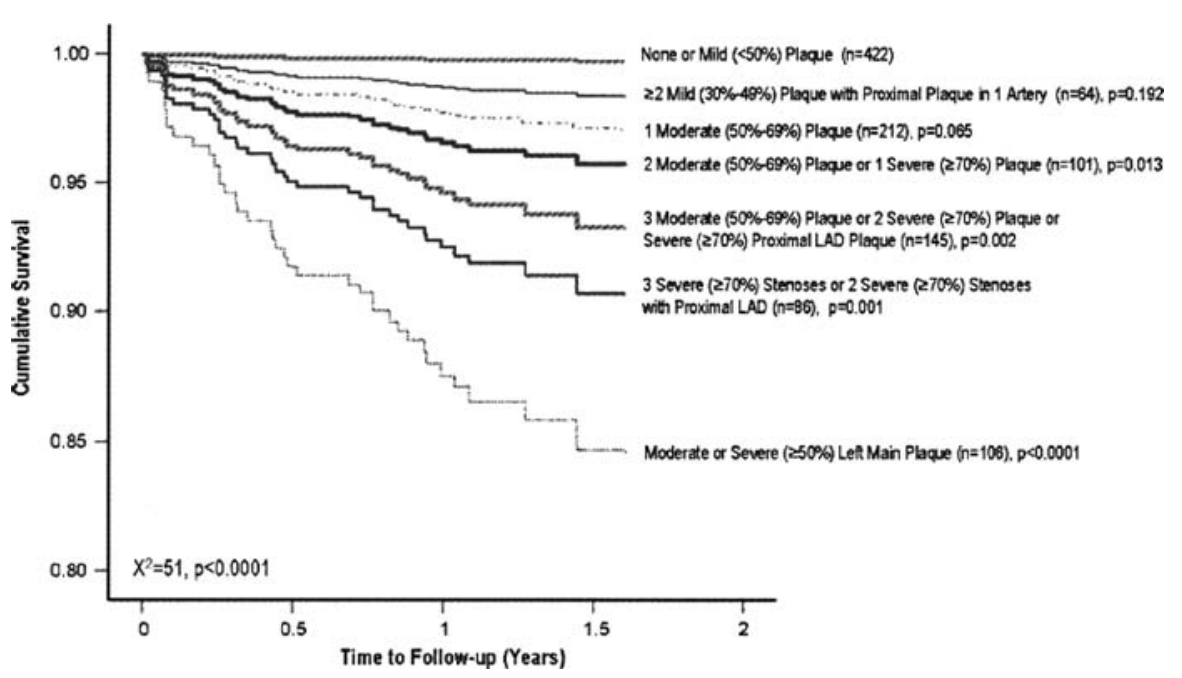

the precise relative prognostic values of anatomical and functional techniques remain not fully defined at present and may highly depend on the patient population that is studied. Although their combination may enhance risk stratification, one should realize that it is at the cost of increased radiation burden. Further research is required to identify those patients that may substantially benefit from comprehensive anatomical and functional assessment. However, recent innovations in MSCT technology and acquisition protocols, such as prospective ECG-triggering, have resulted in substantial dose reduction without loss of image quality [38]. Moreover, Herzog et al. recently demonstrated that also the high diagnostic accuracy and high negative predictive value of the technique in particular, were maintained at an average radiation dose as low as $2.1 \pm 0.7 \mathrm{mSv}$ (range: 1.0-3.3) [39]. Importantly these recent developments are currently also being implemented in hybrid systems and recent data have confirmed the feasibility of low dose $(\leq 10 \mathrm{mSv})$ hybrid PET/CT and even SPECT/CT [40, 41].

\section{Developments in imaging of cardiac structures and function}

\section{LV function assessment using MSCT}

LV function serves as a valuable prognostic and diagnostic marker in patients with CAD [42, 43] and can be evaluated with MSCT. Depending on the MSCT acquisition technique, retrospective reconstruction of cardiac images in any tomographic plane throughout the cardiac cycle is possible. To assess global LV function, 10 or 20 cine-loops are in general obtained by reconstructing thick slices $(2 \mathrm{~mm})$ in the short-axis orientation throughout the R-R interval (in steps of 5 or $10 \%$ ). Subsequently, end-systolic and diastolic phases are determined by selecting the smallest and largest cross-sectional LV cavity areas. Specialized software is used for semi-manual or since more recently fully automatic delineation of the endocardial borders of the appropriate phases [44]. Based on the Simpson method, end-diastolic and systolic volumes are subsequently derived and the LV ejection fraction (LVEF) is calculated. More recently also dedicated volumetric algorithms have become available. These algorithms use the high contrast between the LV cavity and myocardium to derive LV volumes following manual or automated definition of the mitral valve plane and LV axis.

The feasibility of LV function evaluation with MSCT has been investigated extensively. Numerous studies have shown good agreement for the assessment of global LV function between MSCT and 2Dechocardiography [45, 46]. Good agreement was demonstrated for LVEF by Wu et al., as determined by 64-slice MSCT and 2D-echocardiography in 63 patients $(r=0.87, P<0.001)$ [47]. In addition, excellent correlations have also been observed between measurements obtained by MSCT and magnetic resonance imaging (MRI), which is regarded as the gold standard for non-invasive quantification of LV function [48-50]. Moreover, Yamamuro et al. showed that measurements between MSCT and MRI were more closely related than 
measurements between 2D-echocardiography and MRI, suggesting that MSCT may be even more accurate than 2D-echocardiography in the evaluation of LV function [51]. This may be explained by the fact that, while echocardiography relies on a geometrical assumption of two-dimensional images, MSCT uses true three-dimensional endocardial border definition.

In addition to global LV function assessment, MSCT allows evaluation of regional wall motion by displaying the images in cine-loop. Previously, Henneman et al. showed excellent agreement for regional wall motion between 64-slice MSCT and 2D-echocardiography, with $96 \%$ of segments scored identically on both modalities (kappa $=0.73$ ) [52]. Mahnken et al. assessed regional wall motion using 16-slice MSCT in comparison to cardiac MRI. In line with other investigations, the investigators observed a good agreement between the two modalities, with $86 \%$ of segments scored identically $(k=0.79)$ [53].

It is important to realize that with previous standard MSCT acquisition protocols, LV function measurements could be obtained retrospectively from the same data set acquired for coronary angiography. Thus, LV function could be assessed without the need for additional acquisitions. Recently, prospective ECG gating protocols have been introduced. With these protocols, data are acquired during a small part of the cardiac cycle. As a result, radiation dose is substantially reduced but assessment of LV function is no longer possible. Of note, when ECG pulsing or dosemodulation is applied, LV function can still be reliably assessed despite the increased noise during systole. Nevertheless, the radiation dose associated with this approach remains higher as compared to when data are acquired prospectively only during diastole. Therefore, the necessity for LV function analysis should be carefully considered for each individual patient.

Imaging of pulmonary vein anatomy with MSCT

In addition to assessment of CAD, the role of MSCT within catheter ablation procedures has increased substantially. An increasing number of patients presents with atrial fibrillation and is subsequently referred for treatment by means of catheter ablation. Since the aim of this procedure is to electronically isolate the pulmonary veins, detailed knowledge of left atrial and pulmonary vein anatomy both prior and during the procedure is important. Previous studies have demonstrated that among patients with atrial fibrillation, a considerable variation in pulmonary vein anatomy, including the presence of a common ostium of the pulmonary veins or the presence of additional pulmonary veins, exists [54]. These anatomical variations can be easily recognized on MSCT with higher accuracy as compared to other techniques [55]. In addition, knowledge of variations in anatomy and size of related structures such as atrial appendage, roof and septum is important and may facilitate the catheter ablation procedure [56]. Moreover, close proximity of surrounding structures such as the esophagus and the coronary arteries can be identified with MSCT beforehand. Based on this information, the individual ablation strategy may be adapted to avoid complications such as atrioesophageal fistula and coronary artery injury.

Extensive effort is currently invested in the integration of the MSCT images with the electrophysiological data in order to have accurate electroanatomical images available on-line during the catheter ablation procedure. Several studies have indicated that fusion of these data is indeed feasible with only minor registration errors (ranging from 1.6 to $2.1 \mathrm{~mm}$ on average) [57]. Moreover, preliminary data indicate that integrated use of MSCT during the catheter ablation procedure may substantial reduce procedural and importantly also fluoroscopy times [58]. In a recent study, Kistler et al. observed a significant reduction in average fluoroscopy time from $62 \pm 26$ min using only the electrophysiological images to $49 \pm 27 \mathrm{~min}$ when integrated electroanatomical images were available [58]. Also, an improvement in procedural success was observed.

Thus, detailed anatomical information obtained by MSCT may be helpful to facilitate catheter ablation procedures and may have the potential to improve procedural success as well reducing complications. However, thus far only small studies are available and larger, randomized trials are needed to confirm that integrated use of MSCT will eventually improve outcome after catheter ablation.

Imaging of mitral and aortic valve anatomy with MSCT

Although echocardiography remains the cornerstone in the evaluation of valvular heart disease, recent data 
have demonstrated the feasibility of MSCT to accurately study mitral and aortic valve anatomy and function [59-64]. By using multiphase data sets obtained during ECG gating, the leaflet or cusp motion can be evaluated in cine loop. For this purpose, ten image data sets are usually reconstructed at each $10 \%$ of the R-R interval similar as described for the assessment of LV function. For mitral valve evaluation, perpendicular planes images of the valve are preferred, whereas for aortic valve study the cross-sectional image plane perpendicular to the valve cusps illustrates precisely the morphology of the valve (Fig. 4).

The opportunity to non-invasively visualize valvular anatomy and surrounding structures may be of particular interest in the setting of percutaneous valve repair or replacement (PVR) techniques. These techniques have been recently introduced as an alternative therapy for those patients ineligible for surgery due to high perioperative risk, elderly age or comorbidity [65-67]. Although transesophageal echocardiography along with fluoroscopy will remain the most important imaging techniques to guide PVR procedures, several technical aspects related to these procedures require an exact, detailed depiction of the valvular anatomy and morphology to reach the highest procedural success. In this new clinical field, three-dimensional high-resolution imaging with MSCT may be of great value.

Particularly, before performing a coronary sinus annuloplasty, one of the current percutaneous approaches for mitral valve repair, an exact study of the anatomical relation between the mitral annulus and the coronary sinus is required. The feasibility of this percutaneous procedure depends on the distance between the coronary sinus and the mitral annulus, but also, on the anatomical relation of these two structures with the course of the left circumflex coronary artery (LCx). The left atrial enlargement and the mitral annular dilatation usually observed in patients with severe mitral regurgitation result in an abnormal separation between the coronary sinus and the mitral annulus. In those clinical scenarios, the implantation of the device through the coronary sinus results in inefficient remodeling of the mitral annulus and unsuccessful procedure. So far, two studies have investigated the anatomical relation between the coronary sinus, the mitral annulus and the LCx using MSCT. Choudre et al. studied 14 patients with mitral valve prolapse
Fig. 4 Assessment of the anatomy of cardiac valves with MSCT. a A sagittal plane of the left-side valves with severe calcification of both the aortic and mitral annulus (arrows). The cross-sectional plane of the mitral annulus

(b) demonstrates the extent of calcification spreading towards the left ventricular outflow tract (LVOT). Mixomatous mitral valve can be also imaged by MSCT, showing thickened mitral leaflets (c, arrows). The cross-sectional plane of the aortic valve demonstrates the anatomy of the valve (tricuspid/ bicuspid) and the extent of calcification (d)
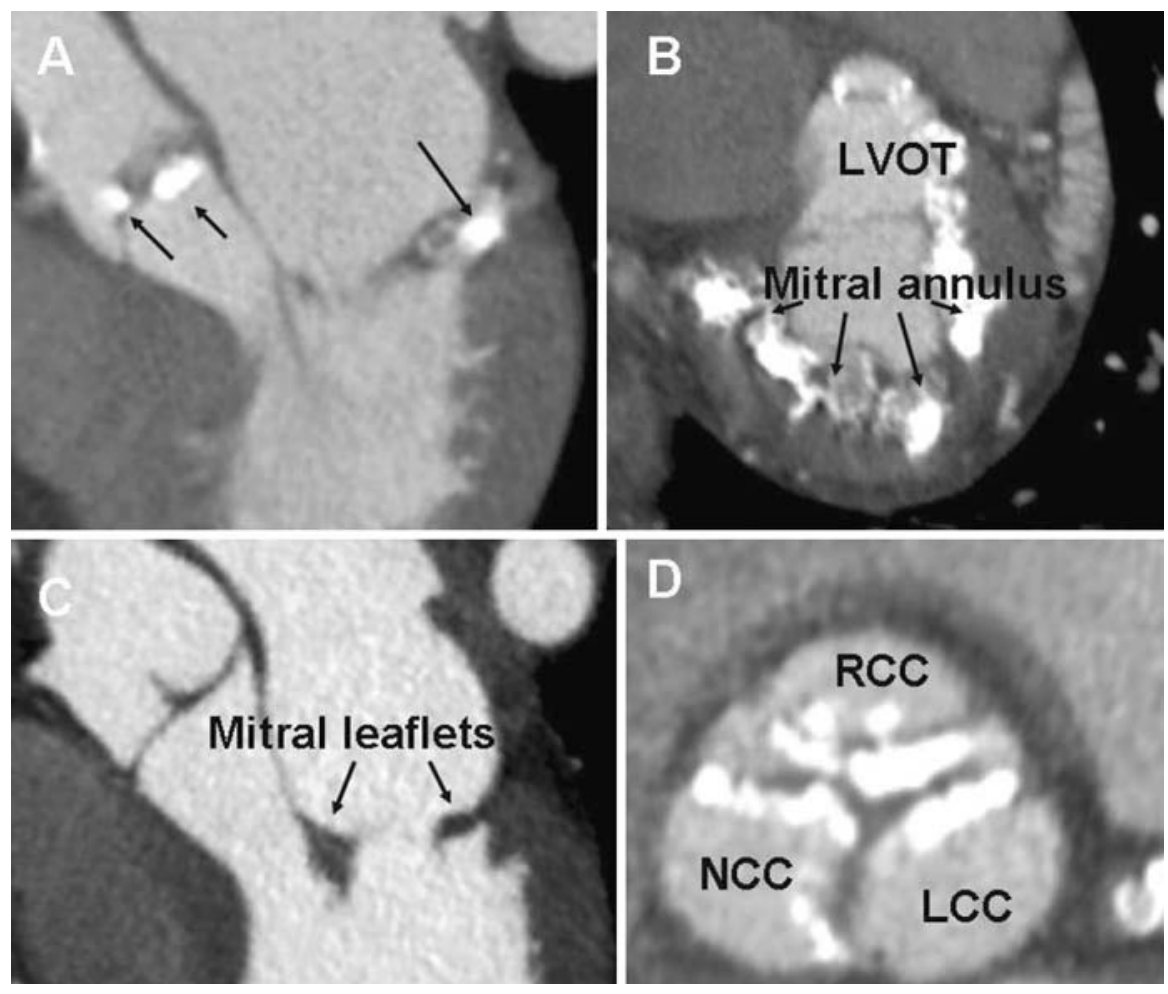
who were scanned with $16-$ or 40-MSCT, and observed that the distance between the coronary sinus and the mitral annulus increased proportionally with the mitral annular dilatation in the posterolateral location [68]. Furthermore, in $80 \%$ of the patients the LCx crossed between the coronary sinus and the mitral annulus, indicating the risk of impingement of the epicardial artery and the subsequent myocardial infarction. These findings were confirmed by Tops and coworkers, who compared observations with 64-slice MSCT in15 patients with severe mitral regurgitation to 90 patients without [69]. The authors observed a course of the coronary sinus located superiorly to the mitral annulus in the majority of the patients (95\%), with an increasing distance in patients with severe mitral regurgitation as compared to patients without. In addition, the LCx was located between the coronary sinus and the mitral annulus in $68 \%$ of the patients. Accordingly, MSCT may become an important imaging technique to select potential candidates for percutaneous mitral valve repair.

Similarly, percutaneous aortic valve replacement has emerged as a potential alternative approach in the treatment of patients with severe symptomatic aortic stenosis [70-73]. To assure a high procedural success-rate, an optimal selection of the potential candidates is necessary. For this purpose, an exact aortic annulus sizing and a detailed anatomical description of the aortic root and the surrounding structures, including the coronary ostia, are crucial to avoid complications such as the presence of significant paravalvular aortic regurgitation or coronary occlusion by a bulky leaflet after device deployment. In addition, knowledge of the amount of calcification and the morphology of the aortic valve (tricuspid or bicuspid) is also highly relevant. Indeed, excessive calcification of the valve or a bicuspid morphology may result in misdeployment of the device and higher risk of complications (paravalvular leakage or
Fig. 5 Assessment of the aortic valve prior to and after PVR with MSCT. Before percutaneous aortic valve replacement, the distance between the aortic annulus and the left and right coronary ostia may be of great value in order to estimate the risk of coronary ostium occlusion by a bulky leaflet (a and b). After prosthesis implantation, the optimal deployment of the device and the patency of the coronary ostia can be assessed by MSCT (c and d)
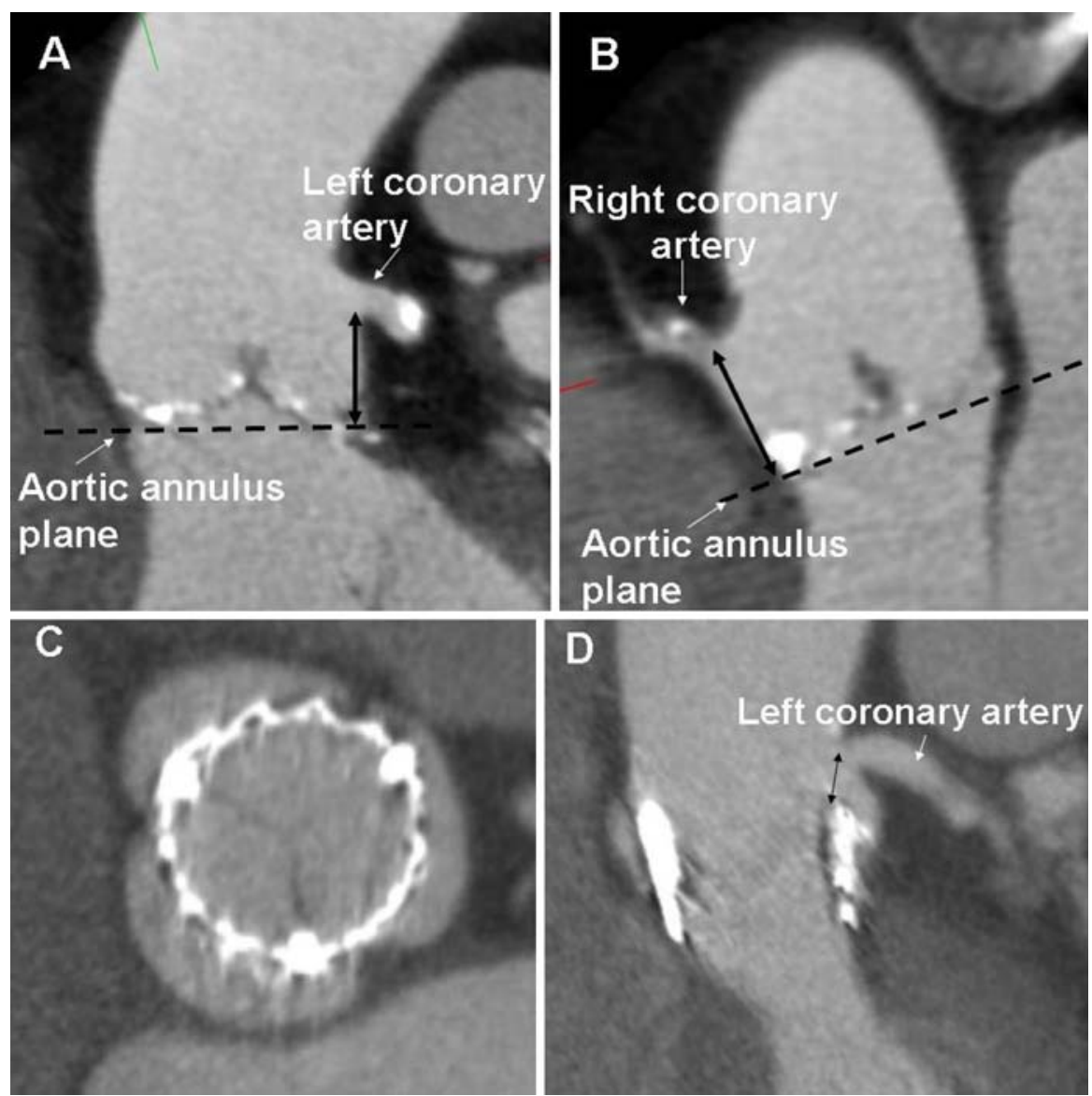
prosthesis embolization) [74, 75]. Accordingly preoperative knowledge of these aspects obtained by MSCT may influence the choice of valvular prosthesis type as well as valve replacement strategy. The feasibility of MSCT in this regard was recently investigated by Tops et al., who performed an extensive assessment of the aortic root anatomy using 64-MSCT in 169 patients, including 19 patients with aortic stenosis [76]. The main findings of this study included an oval-shape of the aortic annulus, with larger diameter in the coronal images $(26.7 \pm 3.9 \mathrm{~mm})$ than in the sagittal images $(24.2 \pm 3 \mathrm{~mm})$. In addition, a variable height of the coronary ostia (Fig. 5) was observed with the length of the left coronary leaflet exceeding the distance between the annulus and the left coronary ostium in $49 \%$ of patients. Accordingly the authors concluded that MSCT may indeed provide detailed and clinically relevant information on the shape of the aortic annulus as well as its relation with the ostia of the coronary arteries. Potentially, MSCT may also be of value in assessing prosthesis deployment and positioning after the procedure (Fig. 5). Prospective studies should address whether assessment with MSCT may indeed improve selection of potential candidates for PVR procedures and improve procedural success and outcome.

\section{Summary and conclusions}

During the past few years MSCT has rapidly developed into a versatile non-invasive imaging modality. While imaging of the coronary arteries to determine or rule out the presence of CAD will remain one of the main indications, additional information on plaque severity and composition can be obtained. Potentially this particular feature may provide clinically relevant information with regard to risk stratification. Notably, imaging with MSCT is not restricted to the coronary arteries as the entire heart is visualized high resolution. Accordingly, comprehensive cardiac assessment is possible and as a result, the technique has a high potential for several other cardiac applications, including guidance of interventional procedures such as catheter ablation in atrial fibrillation or PVR in valvular heart disease. Importantly, the improvements in image quality and accuracy have been paralleled by simultaneous effective dose reduction, broadening acceptance of this promising imaging modality. Nevertheless, as the technique is relatively new, only limited data are currently available. Large prospective studies are needed to validate these novel applications of MSCT for use in daily clinical practice.

Open Access This article is distributed under the terms of the Creative Commons Attribution Noncommercial License which permits any noncommercial use, distribution, and reproduction in any medium, provided the original author(s) and source are credited.

\section{References}

1. Vanhoenacker PK, Heijenbrok-Kal MH, Van Heste R, Decramer I, Van Hoe LR, Wijns W et al (2007) Diagnostic performance of multidetector CT angiography for assessment of coronary artery disease: meta-analysis. Radiology 244(2):419-428. doi:10.1148/radiol.2442061218

2. Leber AW, Knez A, von Ziegler F, Becker A, Nikolaou K, Paul S et al (2005) Quantification of obstructive and nonobstructive coronary lesions by 64-slice computed tomography: a comparative study with quantitative coronary angiography and intravascular ultrasound. J Am Coll Cardiol 46(1):147-154. doi:10.1016/j.jacc.2005.03.071

3. Leber AW, Becker A, Knez A, von Ziegler F, Sirol M, Nikolaou K et al (2006) Accuracy of 64-slice computed tomography to classify and quantify plaque volumes in the proximal coronary system: a comparative study using intravascular ultrasound. J Am Coll Cardiol 47(3):672677. doi:10.1016/j.jacc.2005.10.058

4. Otsuka M, Bruining N, Van Pelt NC, Mollet NR, Ligthart JM, Vourvouri E et al (2008) Quantification of coronary plaque by 64-slice computed tomography: a comparison with quantitative intracoronary ultrasound. Investig Radiol 43(5):314-321. doi:10.1097/RLI.0b013e31816a88a9

5. Bruining N, Roelandt JR, Palumbo A, La Grutta L, Cademartiri F, de Feijter PJ et al (2007) Reproducible coronary plaque quantification by multislice computed tomography. Catheter Cardiovasc Interv 69(6):857-865. doi:10.1002/ccd.21067

6. Marquering HA, Dijkstra J, de Koning PJ, Stoel BC, Reiber JH (2005) Towards quantitative analysis of coronary CTA. Int J Cardiovasc Imaging 21(1):73-84. doi:10.1007/ s10554-004-5341-y

7. Gaemperli O, Schepis T, Koepfli P, Valenta I, Soyka J, Leschka S et al (2007) Accuracy of 64-slice CT angiography for the detection of functionally relevant coronary stenoses as assessed with myocardial perfusion SPECT. Eur J Nucl Med Mol Imaging 34(8):1162-1171. doi: 10.1007/s00259-006-0307-z

8. Schuijf JD, Wijns W, Jukema JW, Atsma DE, de Roos A, Lamb HJ et al (2006) Relationship between noninvasive coronary angiography with multi-slice computed tomography and myocardial perfusion imaging. J Am Coll Cardiol 48(12):2508-2514. doi:10.1016/j.jacc.2006.05.080 
9. Meijboom WB, van Mieghem CA, van Pelt N, Weustink A, Pugliese F, Mollet NR et al (2008) Comprehensive assessment of coronary artery stenoses: computed tomography coronary angiography versus conventional coronary angiography and correlation with fractional flow reserve in patients with stable angina. J Am Coll Cardiol 52(8):636643. doi:10.1016/j.jacc.2008.05.024

10. Myerburg RJ (1997) Frequency of sudden cardiac death and profiles of risk. Am J Cardiol 80(5B):10F-19F. doi: 10.1016/S0002-9149(97)00477-3

11. Kolodgie FD (2004) Pathologic assessment of the vulnerable human coronary plaque. Heart 90(12):1385-1391. doi: 10.1136/hrt.2004.041798

12. Kopp AF, Schroeder S, Baumbach A, Kuettner A, Georg C, Ohnesorge B et al (2001) Non-invasive characterisation of coronary lesion morphology and composition by multislice CT: first results in comparison with intracoronary ultrasound. Eur Radiol 11(9):1607-1611. doi:10.1007/ s003300100850

13. Leber AW, Knez A, Becker A, Becker C, von ZF, Nikolaou K et al (2004) Accuracy of multidetector spiral computed tomography in identifying and differentiating the composition of coronary atherosclerotic plaques: a comparative study with intracoronary ultrasound. J Am Coll Cardiol 43(7):1241-1247. doi:10.1016/j.jacc.2003. 10.059

14. Schroeder S, Kopp AF, Baumbach A, Meisner C, Kuettner A, Georg C et al (2001) Noninvasive detection and evaluation of atherosclerotic coronary plaques with multislice computed tomography. J Am Coll Cardiol 37(5):14301435. doi:10.1016/S0735-1097(01)01115-9

15. Motoyama S, Kondo T, Anno H, Sugiura A, Ito Y, Mori K et al (2007) Atherosclerotic plaque characterization by 0.5 mm-slice multislice computed tomographic imaging. Circ J 71(3):363-366. doi:10.1253/circj.71.363

16. Pohle K, Achenbach S, Macneill B, Ropers D, Ferencik M, Moselewski $F$ et al (2007) Characterization of non-calcified coronary atherosclerotic plaque by multi-detector row CT: comparison to IVUS. Atherosclerosis 190(1):174-180. doi:10.1016/j.atherosclerosis.2006.01.013

17. Pundziute G, Schuijf JD, Jukema JW, Decramer I, Sarno G, Vanhoenacker PK et al (2008) Head-to-head comparison of coronary plaque evaluation between multi-slice computed tomography and intravascular ultrasound radiofrequency data analysis. J Am Coll Cardiol Cardiovasc Interv 1(2):176-182. doi:10.1016/j.jcin.2008.01.007

18. Motoyama S, Kondo T, Sarai M, Sugiura A, Harigaya H, Sato $\mathrm{T}$ et al (2007) Multislice computed tomographic characteristics of coronary lesions in acute coronary syndromes. J Am Coll Cardiol 50(4):319-326. doi:10.1016/ j.jacc.2007.03.044

19. Lin F, Shaw LJ, Berman DS, Callister TQ, Weinsaft JW, Wong FJ et al (2008) Multidetector computed tomography coronary artery plaque predictors of stress-induced myocardial ischemia by SPECT. Atherosclerosis 197(2):700709. doi:10.1016/j.atherosclerosis.2007.07.002

20. LeberAW, KnezA, WhiteCW, BeckerA, vonZF, Muehling O et al (2003) Composition of coronary atherosclerotic plaques in patients with acute myocardial infarction and stable angina pectoris determined by contrast-enhanced multislice computed tomography. Am J Cardiol 91(6):714-718. doi: 10.1016/S0002-9149(02)03411-2

21. Hoffmann U, Moselewski F, Nieman K, Jang I, Ferencik M, Rahman A (2006) Noninvasive assessment of plaque morphology and composition in culprit and stable lesions in acute coronary syndrome and stable lesions in stable angina by multidetector computed tomography. J Am Coll Cardiol 47(8):1655-1662. doi:10.1016/j.jacc.2006.01.041

22. Pundziute G, Schuijf JD, Jukema JW, Decramer I, Sarno G, Vanhoenacker PK et al (2008) Evaluation of plaque characteristics in acute coronary syndromes: non-invasive assessment with multi-slice computed tomography and invasive evaluation with intravascular ultrasound radiofrequency data analysis. Eur Heart J 29:2373-2381

23. Schuijf JD, Beck T, Burgstahler C, Jukema JW, Dirksen MS, de Roos A et al (2007) Differences in plaque composition and distribution in stable coronary artery disease versus acute coronary syndromes; non-invasive evaluation with multi-slice computed tomography. Acute Card Care 9(1):48-53. doi:10.1080/17482940601052648

24. Hyafil F, Cornily JC, Feig JE, Gordon R, Vucic E, Amirbekian $\mathrm{V}$ et al (2007) Noninvasive detection of macrophages using a nanoparticulate contrast agent for computed tomography. Nat Med 13(5):636-641. doi: $10.1038 / \mathrm{nm} 1571$

25. Boll DT, Hoffmann MH, Huber N, Bossert AS, Aschoff AJ, Fleiter TR (2006) Spectral coronary multidetector computed tomography angiography: dual benefit by facilitating plaque characterization and enhancing lumen depiction. J Comput Assist Tomogr 30(5):804-811. doi: 10.1097/01.rct.0000228162.70849.26

26. Burgstahler C, Reimann A, Beck T, Kuettner A, Baumann D, Heuschmid M et al (2007) Influence of a lipid-lowering therapy on calcified and noncalcified coronary plaques monitored by multislice detector computed tomography: results of the New Age II Pilot Study. Investig Radiol 42(3):189-195. doi:10.1097/01.rli.0000254408.96355.85

27. Ibanez B et al (2009) Quantification of serial changes in plaque burden using multi-detector computed tomography in experimental atherosclerosis. Atherosclerosis 202(1):185-191. doi:10.1016/j.atherosclerosis.2008.03.019

28. Greenland P, Bonow RO, Brundage BH, Budoff MJ, Eisenberg MJ, Grundy SM et al (2007) ACCF/AHA 2007 clinical expert consensus document on coronary artery calcium scoring by computed tomography in global cardiovascular risk assessment and in evaluation of patients with chest pain: a report of the American College of Cardiology Foundation Clinical Expert Consensus Task Force (ACCF/AHA writing committee to update the 2000 expert consensus document on electron beam computed tomography) developed in collaboration with the Society of Atherosclerosis Imaging and Prevention and the Society of Cardiovascular Computed Tomography. J Am Coll Cardiol 49(3):378-402. doi:10.1016/ j.jacc.2006.10.001

29. Shaw LJ, Raggi P, Schisterman E, Berman DS, Callister TQ (2003) Prognostic value of cardiac risk factors and coronary artery calcium screening for all-cause mortality. Radiology 228(3):826-833. doi:10.1148/radiol.228302 1006 
30. Budoff MJ, Shaw LJ, Liu ST, Weinstein SR, Mosler TP, Tseng PH et al (2007) Long-term prognosis associated with coronary calcification: observations from a registry of 25 , 253 patients. J Am Coll Cardiol 49(18):1860-1870. doi: 10.1016/j.jacc.2006.10.079

31. Pundziute G, Schuijf JD, Jukema JW, Boersma E, de Roos A, van der Wall EE et al (2007) Prognostic value of multislice computed tomography coronary angiography in patients with known or suspected coronary artery disease. J Am Coll Cardiol 49(1):62-70. doi:10.1016/j.jacc.2006.07. 070

32. Min JK, Shaw LJ, Devereux RB, Okin PM, Weinsaft JW, Russo DJ et al (2007) Prognostic value of multidetector coronary computed tomographic angiography for prediction of all-cause mortality. J Am Coll Cardiol 50(12):1161-1170. doi:10.1016/j.jacc.2007.03.067

33. Anand DV, Lim E, Hopkins D, Corder R, Shaw LJ, Sharp $P$ et al (2006) Risk stratification in uncomplicated type 2 diabetes: prospective evaluation of the combined use of coronary artery calcium imaging and selective myocardial perfusion scintigraphy. Eur Heart J 27(6):713-721. doi: 10.1093/eurheartj/ehi808

34. Ramakrishna G, Breen JF, Mulvagh SL, McCully RB, Pellikka PA (2006) Relationship between coronary artery calcification detected by electron-beam computed tomography and abnormal stress echocardiography: association and prognostic implications. J Am Coll Cardiol 48(10): 2125-2131. doi:10.1016/j.jacc.2006.04.105

35. Rozanski A, Gransar H, Wong ND, Shaw LJ, MirandaPeats R, Polk D et al (2007) Clinical outcomes after both coronary calcium scanning and exercise myocardial perfusion scintigraphy. J Am Coll Cardiol 49(12):1352-1361. doi:10.1016/j.jacc.2006.12.035

36. Schenker MP, Dorbala S, Hong EC, Rybicki FJ, Hachamovitch R, Kwong RY et al (2008) Interrelation of coronary calcification, myocardial ischemia, and outcomes in patients with intermediate likelihood of coronary artery disease: a combined positron emission tomography/computed tomography study. Circulation 117(13):1693-1700. doi:10.1161/CIRCULATIONAHA.107.717512

37. van Werkhoven JM, Schuijf JD, Gaemperli O, Jukema JW, Boersma E, Wijns W et al (2009) Prognostic value of multi-slice computed tomography and gated single photon emission computed tomography in patients with suspected coronary artery disease. J Am Coll Cardiol (in press)

38. Husmann L, Valenta I, Gaemperli O, Adda O, Treyer V, Wyss CA et al (2008) Feasibility of low-dose coronary CT angiography: first experience with prospective ECG-gating. Eur Heart J 29(2):191-197. doi:10.1093/eurheartj/ehm613

39. Herzog BA, Husmann L, Burkhard N, Gaemperli O, Valenta I, Tatsugami F et al (2008) Accuracy of low-dose computed tomography coronary angiography using prospective electrocardiogram-triggering: first clinical experience. Eur Heart J 29(24):3037-3042. doi:10.1093/ eurheartj/ehn485

40. Kajander S, Ukkonen H, Sipila H, Teras M, Knuuti J (2009) Low radiation dose imaging of myocardial perfusion and coronary angiography with a hybrid PET/CT scanner. Clin Physiol Funct Imaging 29(1):81-88. doi: 10.1111/j.1475-097X.2008.00838.X
41. Herzog BA, Husmann L, Landmesser U, Kaufmann PA (2008) Low-dose computed tomography coronary angiography and myocardial perfusion imaging: cardiac hybrid imaging below $3 \mathrm{mSv}$. Eur Heart J. doi:10.1093/ eurheartj/ehn490

42. Emond M, Mock MB, Davis KB, Fisher LD, Holmes DR Jr, Chaitman BR et al (1994) Long-term survival of medically treated patients in the coronary artery surgery study (CASS) registry. Circulation 90(6):2645-2657

43. Hofmann T, Meinertz T, Kasper W, Geibel A, Zehender M, Hohnloser S et al (1988) Mode of death in idiopathic dilated cardiomyopathy: a multivariate analysis of prognostic determinants. Am Heart J 116(6 Pt 1):1455-1463

44. Dogan H, Kroft LJ, Bax JJ, Schuijf JD, van der Geest RJ, Doornbos $\mathrm{J}$ et al (2006) MDCT assessment of right ventricular systolic function. AJR Am J Roentgenol 186((6, Suppl 2)):S366-S370. doi:10.2214/AJR.05.0639

45. Kim TH, Hur J, Kim SJ, Kim HS, Choi BW, Choe KO et al (2005) Two-phase reconstruction for the assessment of left ventricular volume and function using retrospective ECGgated MDCT: comparison with echocardiography. AJR Am J Roentgenol 185(2):319-325

46. Henneman MM, Schuijf JD, Jukema JW, Holman ER, Lamb HJ, de Roos A et al (2006) Assessment of global and regional left ventricular function and volumes with 64-slice MSCT: a comparison with 2D echocardiography. J Nucl Cardiol 13(4):480-487. doi:10.1016/j.nuclcard. cc2006.03.005

47. Wu YW, Tadamura E, Yamamuro M, Kanao S, Okayama $\mathrm{S}$, Ozasa $\mathrm{N}$ et al (2008) Estimation of global and regional cardiac function using 64-slice computed tomography: a comparison study with echocardiography, gated-SPECT and cardiovascular magnetic resonance. Int $\mathrm{J}$ Cardiol 128(1):69-76. doi:10.1016/j.ijcard.2007.06.017

48. Higgins CB (1992) Which standard has the gold? J Am Coll Cardiol 19(7):1608-1609

49. Dewey M, Muller M, Eddicks S, Schnapauff D, Teige F, Rutsch W et al (2006) Evaluation of global and regional left ventricular function with 16-slice computed tomography, biplane cineventriculography, and two-dimensional transthoracic echocardiography: comparison with magnetic resonance imaging. J Am Coll Cardiol 48(10):2034-2044. doi:10.1016/j.jacc.2006.04.104

50. Sugeng L, Mor-Avi V, Weinert L, Niel J, Ebner C, Steringer-Mascherbauer $\mathrm{R}$ et al (2006) Quantitative assessment of left ventricular size and function: side-byside comparison of real-time three-dimensional echocardiography and computed tomography with magnetic resonance reference. Circulation 114(7):654-661. doi: 10.1161/CIRCULATIONAHA.106.626143

51. Yamamuro M, Tadamura E, Kubo S, Toyoda H, Nishina T, Ohba $M$ et al (2005) Cardiac functional analysis with multi-detector row $\mathrm{CT}$ and segmental reconstruction algorithm: comparison with echocardiography, SPECT, and MR imaging. Radiology 234(2):381-390. doi: 10.1148/radiol.2342031271

52. Henneman MM, Bax JJ, Schuijf JD, Jukema JW, Holman ER, Stokkel MP et al (2006) Global and regional left ventricular function: a comparison between gated SPECT, 2D echocardiography and multi-slice computed 
tomography. Eur J Nucl Med Mol Imaging 33(12):14521460. doi:10.1007/s00259-006-0158-7

53. Mahnken AH, Koos R, Katoh M, Spuentrup E, Busch P, Wildberger JE et al (2005) Sixteen-slice spiral CT versus MR imaging for the assessment of left ventricular function in acute myocardial infarction. Eur Radiol 15(4):714-720. doi:10.1007/s00330-004-2592-X

54. Marom EM, Herndon JE, Kim YH, McAdams HP (2004) Variations in pulmonary venous drainage to the left atrium: implications for radiofrequency ablation. Radiology 230(3):824-829. doi:10.1148/radiol.2303030315

55. Jongbloed MR, Bax JJ, Lamb HJ, Dirksen MS, Zeppenfeld $\mathrm{K}$, van der Wall EE et al (2005) Multislice computed tomography versus intracardiac echocardiography to evaluate the pulmonary veins before radiofrequency catheter ablation of atrial fibrillation: a head-to-head comparison. J Am Coll Cardiol 45(3):343-350. doi:10.1016/j.jacc.2004. 10.040

56. Wongcharoen W, Tsao HM, Wu MH, Tai CT, Chang SL, Lin YJ et al (2006) Morphologic characteristics of the left atrial appendage, roof, and septum: implications for the ablation of atrial fibrillation. J Cardiovasc Electrophysiol 17(9):951-956. doi:10.1111/j.1540-8167.2006.00549.x

57. Tops LF, Bax JJ, Zeppenfeld K, Jongbloed MR, Lamb HJ, van der Wall EE et al (2005) Fusion of multislice computed tomography imaging with three-dimensional electroanatomic mapping to guide radiofrequency catheter ablation procedures. Heart Rhythm 2(10):1076-1081. doi: 10.1016/j.hrthm.2005.07.019

58. Kistler PM, Rajappan K, Jahngir M, Earley MJ, Harris S, Abrams D et al (2006) The impact of CT image integration into an electroanatomic mapping system on clinical outcomes of catheter ablation of atrial fibrillation. J Cardiovasc Electrophysiol 17(10):1093-1101. doi:10.1111/j.15408167.2006.00594.x

59. Alkadhi H, Wildermuth S, Bettex DA, Plass A, Baumert B, Leschka $S$ et al (2006) Mitral regurgitation: quantification with 16-detector row CT-initial experience. Radiology 238(2):454-463. doi:10.1148/radiol.2381042216

60. Alkadhi H, Desbiolles L, Husmann L, Plass A, Leschka S, Scheffel H et al (2007) Aortic regurgitation: assessment with 64-section CT. Radiology 245(1):111-121. doi: 10.1148/radiol.2451061523

61. Feuchtner GM, Dichtl W, Muller S, Jodocy D, Schachner T, Klauser A et al (2008) 64-MDCT for diagnosis of aortic regurgitation in patients referred to CT coronary angiography. AJR Am J Roentgenol 191(1):W1-W7. doi: 10.2214/AJR.07.3432

62. Jassal DS, Shapiro MD, Neilan TG, Chaithiraphan V, Ferencik M, Teague SD et al (2007) 64-slice multidetector computed tomography (MDCT) for detection of aortic regurgitation and quantification of severity. Investig Radiol 42(7):507-512. doi:10.1097/RLI.0b013e3180375556

63. Messika-Zeitoun D, Serfaty JM, Laissy JP, Berhili M, Brochet E, Iung B et al (2006) Assessment of the mitral valve area in patients with mitral stenosis by multislice computed tomography. J Am Coll Cardiol 48(2):411-413. doi:10.1016/j.jacc.2006.04.035

64. Pouleur AC, le Polain de Waroux JB, Pasquet A, Vanoverschelde JL, Gerber BL (2007) Aortic valve area assessment: multidetector CT compared with cine MR imaging and transthoracic and transesophageal echocardiography. Radiology 244(3):745-754. doi:10.1148/radiol. 2443061127

65. Iung B, Cachier A, Baron G, Messika-Zeitoun D, Delahaye F, Tornos $\mathrm{P}$ et al (2005) Decision-making in elderly patients with severe aortic stenosis: why are so many denied surgery? Eur Heart J 26(24):2714-2720. doi: 10.1093/eurheartj/ehi471

66. Mirabel M, Iung B, Baron G, Messika-Zeitoun D, Detaint D, Vanoverschelde JL et al (2007) What are the characteristics of patients with severe, symptomatic, mitral regurgitation who are denied surgery? Eur Heart J 28(11):1358-1365. doi:10.1093/eurheartj/ehm001

67. Grube E, Laborde JC, Gerckens U, Felderhoff T, Sauren B, Buellesfeld L et al (2006) Percutaneous implantation of the core valve self-expanding valve prosthesis in high-risk patients with aortic valve disease: the Siegburg first-in-man study. Circulation 114(15):1616-1624. doi:10.1161/ CIRCULATIONAHA.106.639450

68. Choure AJ, Garcia MJ, Hesse B, Sevensma M, Maly G, Greenberg NL et al (2006) In vivo analysis of the anatomical relationship of coronary sinus to mitral annulus and left circumflex coronary artery using cardiac multidetector computed tomography: implications for percutaneous coronary sinus mitral annuloplasty. J Am Coll Cardiol 48(10):1938-1945. doi:10.1016/j.jacc.2006. 07.043

69. Tops LF, Van de Veire NR, Schuijf JD, de Roos A, van der Wall EE, Schalij MJ et al (2007) Noninvasive evaluation of coronary sinus anatomy and its relation to the mitral valve annulus: implications for percutaneous mitral annuloplasty. Circulation 115(11):1426-1432. doi:10.1161/ CIRCULATIONAHA.106.677880

70. Cribier A, Eltchaninoff H, Tron C, Bauer F, Agatiello C, Sebagh L et al (2004) Early experience with percutaneous transcatheter implantation of heart valve prosthesis for the treatment of end-stage inoperable patients with calcific aortic stenosis. J Am Coll Cardiol 43(4):698-703. doi: 10.1016/j.jacc.2003.11.026

71. Descoutures F, Himbert D, Lepage L, Iung B, Detaint D, Tchetche D et al (2008) Contemporary surgical or percutaneous management of severe aortic stenosis in the elderly. Eur Heart J 29(11):1410-1417. doi:10.1093/ eurheartj/ehn081

72. Grube E, Schuler G, Buellesfeld L, Gerckens U, Linke A, Wenaweser P et al (2007) Percutaneous aortic valve replacement for severe aortic stenosis in high-risk patients using the second- and current third-generation selfexpanding CoreValve prosthesis: device success and 30day clinical outcome. J Am Coll Cardiol 50(1):69-76. doi: 10.1016/j.jacc.2007.04.047

73. Webb JG, Chandavimol M, Thompson CR, Ricci DR, Carere RG, Munt BI et al (2006) Percutaneous aortic valve implantation retrograde from the femoral artery. Circulation 113(6):842-850. doi:10.1161/CIRCULATIONAHA. 105.582882

74. Webb JG, Pasupati S, Humphries K, Thompson C, Altwegg L, Moss R et al (2007) Percutaneous transarterial aortic valve replacement in selected high-risk patients with aortic stenosis. Circulation 116(7):755-763. doi:10.1161/ CIRCULATIONAHA.107.698258 
75. Zegdi R, Ciobotaru V, Noghin M, Sleilaty G, Lafont A, Latremouille $\mathrm{C}$ et al (2008) Is it reasonable to treat all calcified stenotic aortic valves with a valved stent? Results from a human anatomic study in adults. J Am Coll Cardiol 51(5):579-584. doi:10.1016/j.jacc.2007.10.023
76. Tops LF, Wood DA, Delgado V, Schuijf JD, Mayo JR, Pasupati S et al (2008) Noninvasive evaluation of the aortic root with multislice computed tomography: implications for transcatheter aortic valve replacement. J Am Coll Cardiol Cardiovasc Imaging 1(3):321-330 